Check for updates

Cite this: RSC Adv., 2017, 7, 34131

\title{
Oxidative dehydrogenation of $n$-butane to butenes on Mo-doped VMgO catalysts
}

\begin{abstract}
Xue Liu, (D) ab Linhai Duan, ${ }^{\star a}$ Weishen Yang (D) ${ }^{b}$ and Xuefeng Zhu (D) *b
VMgO catalysts with different molybdenum doping amounts were prepared by an impregnation method. The structure, specific surface area, and basic and redox properties of these catalysts were determined by XRD, BET, $\mathrm{CO}_{2}-\mathrm{TPD}$, and $\mathrm{H}_{2}-\mathrm{TPR}$. The XRD results revealed that all catalysts contained an orthovanadate phase $\left(\mathrm{Mg}_{3}\left(\mathrm{VO}_{4}\right)_{2}\right)$, while no metavanadate and pyrovanadate phases were detected. BET surface area analysis showed that the Mo-doped catalysts possessed lower surface areas than the undoped one. The reducing and basicity properties of the catalysts were characterized by $\mathrm{H}_{2}$-TPR and $\mathrm{CO}_{2}$-TPD measurements, which demonstrated that Mo-doping improved the redox temperature and reduced the number of basic sites. The performances of these catalysts were investigated at different $\mathrm{C}_{4} \mathrm{H}_{10} / \mathrm{O}_{2}$ molar ratios, temperatures, and contact times. The Mo-doping not only improved the selectivity of butenes but also inhibited the deep oxidation reactions, although cracking reactions occurred with high levels of Mo doping. When the Mo/V atomic ratio was $3: 100, n$-butane conversion of $34.5 \%$ and total butene selectivity of $79.3 \%$ were achieved at $630{ }^{\circ} \mathrm{C}$. To the best of our knowledge, the oxidative dehydrogenation performance of the synthesized Mo-doped VMgO catalysts described in this work represents a remarkable improvement compared to previous reports.
\end{abstract}

Received 2nd May 2017

Accepted 20th June 2017

DOI: $10.1039 / \mathrm{c} 7 \mathrm{ra0} 4936 f$

rsc.li/rsc-advances and $\mathrm{C}_{4}$ selective oxidation reactions occurring in the gas phase over solid catalysts, and suggested that there is a clear limitation in terms of selectivity and conversion, beyond which experimental progresses are difficult to achieve. In their study, the selectivity of $n$-butane to butenes could only reach $60 \%$, when the conversion was $30 \% .^{\mathbf{1 4}}$

The effects of the supports, e.g. $\mathrm{TiO}_{2}, \mathrm{CeO}_{2}, \mathrm{ZrO}_{2}, \mathrm{Al}_{2} \mathrm{O}_{3}$, and $\mathrm{MgO}$, have been widely investigated for V-based catalysts. ${ }^{\mathbf{8} 15-25}$ To the best of our knowledge, $\mathrm{MgO}$ is the best among these supports, and $\mathrm{VMgO}$ catalysts have been extensively studied as highly efficient catalysts for the ODH of $n$-butane..$^{\mathbf{8 , 1 5 2 0 - 2 4}}$ It has been reported that $\mathrm{Mg}_{3}\left(\mathrm{VO}_{4}\right)_{2}$ is the active phase for the ODH of $n$-butane, while other vanadate phases (such as metavanadate and pyrovanadate) are unfavorable for the production of butenes. However, most studies disclosed that the as-prepared control. Therefore, a catalyst with high performance is required for the ODH of $n$-butane. ${ }^{8,9}$ In recent studies, much effort has been devoted to the development of more efficient catalysts in order to achieve both high activity and selectivity. ${ }^{10-13}$ The critical issue related to the ODH of butane is that deep oxidation reactions can occur, leading to the low selectivity of butenes. Costine et al. conducted an extensive data mining study on $\mathrm{C}_{3}$

${ }^{a}$ College of Chemistry, Chemical Engineering and Environmental Engineering, Liaoning Shihua University, Fushun, 113001, P. R. China. E-mail: lhduan@126. com; Tel: +86-024-5686-0757

${ }^{b}$ State Key Laboratory of Catalysis, Dalian Institute of Chemical Physics, Chinese Academy of Sciences, Dalian, 116023, P. R. China. E-mail: zhuxf@dicp.ac.cn; Tel: $+86-411-8437-9182$

\begin{abstract}
catalysts contained minor quantities of other vanadate
\end{abstract}

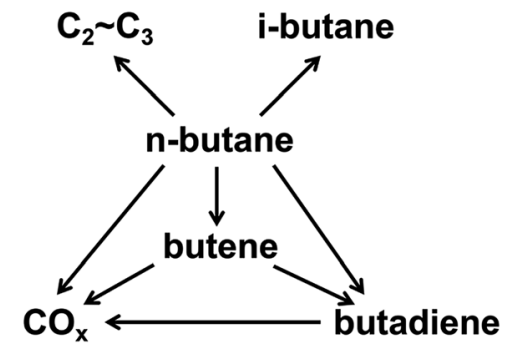

Scheme 1 Reactions of the ODH of $n$-butane. 
phases. ${ }^{22,26}$ Therefore, the preparation method is critical for obtaining a good $\mathrm{VMgO}$ catalyst.

The catalytic performance of the $\mathrm{VMgO}$ catalysts can be slightly improved by adding transition metals, such as $\mathrm{Ni}$, Mo, or Zr. Liu et al. examined the influence of the addition of $\mathrm{Ni}$ to the $\mathrm{VMgO}$ catalysts in the ODH of $n$-butane. The authors found that a moderate doping amount of $\mathrm{Ni}(n(\mathrm{Ni}) / n(\mathrm{~V})=0.3)$ could promote the formation of the $\mathrm{Mg}_{3}\left(\mathrm{VO}_{4}\right)_{2}$ phase and increase the selectivity of butenes. ${ }^{26}$ Dejoz et al. prepared Mo-doped VMgO catalysts with a Mo: $\mathrm{V}$ atomic ratio in the range 0-1.4 to determine the influence of the addition of Mo on the ODH of $n$ butane. The results demonstrated that the Mo-VMgO-based catalysts showed an enhanced selectivity of the $\mathrm{ODH}$ products, and especially to butadiene. However, the selectivity of cracking products increased with increasing Mo-doping amount. ${ }^{15}$ Lee et al. studied $\mathrm{Mg}\left(\mathrm{VO}_{4}\right)_{2} / \mathrm{MgO}-\mathrm{ZrO}_{2}$ catalysts with different $\mathrm{Mg}: \mathrm{Zr}$ ratios. The $\mathrm{MgO}-\mathrm{ZrO}_{2}$ supports were prepared by a gel-oxalate coprecipitation method, while the $\mathrm{Mg}_{3}\left(\mathrm{VO}_{4}\right)_{2} / \mathrm{MgO}-\mathrm{ZrO}_{2}$ catalysts were obtained by a wet impregnation method. The results of this study indicated that $\mathrm{Mg}_{3}\left(\mathrm{VO}_{4}\right)_{2} / \mathrm{MgO}-\mathrm{ZrO}_{2}(\mathrm{Mg}: \mathrm{Zr}$ ratio $=4: 1)$ exhibited the best catalytic performance for the $\mathrm{ODH}$ of $n$-butane, providing a total butenes (including 1-butene, 2-butene, and 1,3-butadiene) yield of $\sim 23 \%{ }^{27}$ Rischard et al. prepared Mo-doped VMgO catalysts, and performed the $\mathrm{ODH}$ reaction at different $\mathrm{O}_{2} / n$-butane molar ratios in a two-zone fluidized bed reactor. When the reaction was conducted at $580{ }^{\circ} \mathrm{C}$ and the $\mathrm{O}_{2} / n$-butane molar ratio was 1.9 , the selectivity of $1,3-\mathrm{C}_{4} \mathrm{H}_{6}$ reached $50.7 \%$ with an $n$-butane conversion of $64.5 \%$. Particularly, the authors reported that the catalysts could be regenerated in a single vessel. ${ }^{28}$

In this work, a series of $10 \mathrm{wt} \% \mathrm{~V}_{2} \mathrm{O}_{5} / \mathrm{MgO}$ catalysts devoid of metavanadate and pyrovanadate phases were prepared via an impregnation method. Oxalic acid was used to dissolve ammonium metavanadate and ammonium molybdate in order to allow a good dispersion of the $\mathrm{V}$ and Mo species on the catalyst surface. The influence of the Mo : $\mathrm{V}$ atomic ratio on the physical and chemical properties was determined by various analytical techniques and the catalytic performance was investigated in a fixed bed reactor. We found that the addition of a small amount of Mo can significantly change the redox and basic properties of the corresponding catalyst, improving the total butenes selectivity.

\section{Experimental}

\subsection{Catalyst preparation}

All catalysts were prepared by an impregnation method. The different Mo : V atomic ratios used were $0,3: 100$, and $5: 100$. The MgO support was pretreated in a muffle furnace at $900{ }^{\circ} \mathrm{C}$ for $3 \mathrm{~h}$. Appropriate amounts of oxalic acid, ammonium metavanadate, and ammonium heptamolybdate were dissolved in deionized water. The mixed solution was added into a beaker containing the $\mathrm{MgO}$ powder and the stirring was continued for $2 \mathrm{~h}$ at room temperature. The resultant slurry was dried at $120{ }^{\circ} \mathrm{C}$ overnight, and then calcined at $700{ }^{\circ} \mathrm{C}$ for $10 \mathrm{~h}$. The resultant powders were pressed into pellets, and then crushed and sieved to 40-60 mesh.

\subsection{Catalyst characterization}

The surface areas of the catalysts were measured using a BET apparatus (OMNISORP 100CX). The crystalline phases of the catalysts were investigated using a XRD diffractometer (Rigaku, $\mathrm{D} / \mathrm{MAX}-\mathrm{RB}$ ) with $\mathrm{Cu} \mathrm{K} \alpha$ radiation operated at $40 \mathrm{kV}$ and $100 \mathrm{~mA}$. The infrared spectra were recorded on a Nicolet 6700 Fouriertransform infrared spectroscopy-attenuated total reflectance (FTIR-ATR, Thermo Scientific Co.) spectrometer. $\mathrm{H}_{2}$ temperature programmed reduction $\left(\mathrm{H}_{2}\right.$-TPR) was performed to elucidate the reducibility of the catalysts using a Chemstar chemisorption analyzer. $\mathrm{CO}_{2}$ temperature programmed desorption ( $\mathrm{CO}_{2}$-TPD) was performed to determine the amount of surface basic sites with a ChemStar chemisorption analyzer.

\subsection{Catalyst performance test}

The ODH of $n$-butane was performed in a fixed bed quartz reactor (10 $\mathrm{mm}$ i.d.) under atmospheric pressure. For each catalytic test, $0.50 \mathrm{~g}$ of catalyst (40-60 mesh) was used. A thermocouple tube with an o.d. of $5 \mathrm{~mm}$ was placed at the center of the quartz reactor. The catalytic reaction conditions were as follows unless otherwise stated: the total space velocity (GHSV) was kept at $58800 \mathrm{~h}^{-1}$; the concentration of $n$-butane at the feed inlet was $2 \mathrm{vol} \%$; the molar ratio of $n$-butane to oxygen was $1: 1$ or $1.5: 1$; nitrogen was used as balance gas. The contact time was adjusted by changing the total flow rate, while maintaining constant the composition of the feed gas mixture. The products of the reaction were analyzed by an online gas chromatograph equipped with a thermal conductivity detector (TCD). The conversion of $n$-butane, selectivity to total butenes (including 1$\mathrm{C}_{4} \mathrm{H}_{8}, 2-t-\mathrm{C}_{4} \mathrm{H}_{8}, 2-c-\mathrm{C}_{4} \mathrm{H}_{8}$, and $1,3-\mathrm{C}_{4} \mathrm{H}_{6}$ ), selectivity to monobutenes (including $1-\mathrm{C}_{4} \mathrm{H}_{8}, 2-t-\mathrm{C}_{4} \mathrm{H}_{8}$, and $2-c-\mathrm{C}_{4} \mathrm{H}_{8}$ ) and selectivities to other products were calculated based on the following equations, respectively:

$$
\begin{gathered}
X_{n-\mathrm{C}_{4} \mathrm{H}_{10}}(\%)=\frac{\sum M_{i} \times n_{i}}{\sum M_{i} \times n_{i}+4 \times m_{n-\mathrm{C}_{4} \mathrm{H}_{10}}} \times 100 \\
S(\%)=\frac{M_{i} \times n_{i}}{\sum M_{i} \times n_{i}} \times 100
\end{gathered}
$$

where $M_{i}$ are the moles of products; $n_{i}$ are the number of carbon atoms of the products, and $m_{n-\mathrm{C}_{4} \mathrm{H}_{10}}$ are the mole of the unreacted $n$-butane, respectively. The carbon balance in this study was in the range of $100 \pm 2 \%$. Relative errors of the conversion and selectivities are less than $1 \%$.

\section{Results and discussion}

\subsection{Catalyst characterization}

The BET surface areas of all the samples before and after the reaction are listed in Table 1 . A slight decrease in the surface area can be noticed as the doping amount of molybdenum increases. The specific surface area of all the catalysts decreased to about $20 \mathrm{~m}^{2} \mathrm{~g}^{-1}$ after the reaction. This decrease may be ascribed to the sintering of the catalysts under the reaction conditions. $^{29}$ 
Table 1 BET specific area of the catalysts with different Mo contents

\begin{tabular}{lllll}
\hline & & & \multicolumn{2}{l}{$S_{\mathrm{BET}} /\left(\mathrm{m}^{2} \mathrm{~g}^{-1}\right)$} \\
\cline { 4 - 5 } Samples & $\begin{array}{l}\mathrm{V}_{2} \mathrm{O}_{5} \\
\text { content }(\mathrm{wt} \%)\end{array}$ & $\begin{array}{l}\mathrm{Mo} / \mathrm{V} \\
\text { atomic ratio }\end{array}$ & $\begin{array}{l}\text { Before } \\
\text { reaction }\end{array}$ & $\begin{array}{l}\text { After } \\
\text { reaction }\end{array}$ \\
\hline $\mathrm{VMgO}$ & 10 & 0 & 44.2 & 22.0 \\
$3 \mathrm{Mo}-\mathrm{VMgO}$ & 10 & $3: 100$ & 33.8 & 21.0 \\
$5 \mathrm{Mo}-\mathrm{VMgO}$ & 10 & $5: 100$ & 26.6 & 17.1
\end{tabular}

Fig. 1 shows the XRD patterns of the as-prepared catalysts. The two crystalline phases can be assigned to MgO (JCPDS no. 45-0946) and $\mathrm{Mg}_{3}\left(\mathrm{VO}_{4}\right)_{2}$ (JCPDS no. 19-0778) respectively. ${ }^{15,30} \mathrm{No}$ metavanadate and pyrovanadate phases were detected, and no Mo-based crystal phase was found due to the extremely low Mo content and its high dispersion in the catalysts. ${ }^{31}$

Fig. 2 shows the FTIR spectra of the as-prepared catalysts. All samples exhibited strong absorption bands at $800-900 \mathrm{~cm}^{-1}$,

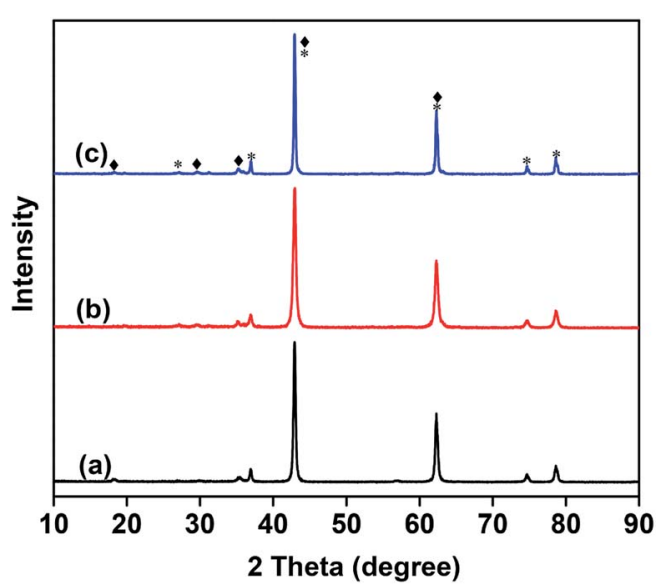

Fig. 1 XRD patterns 10 wt $\% \mathrm{~V}_{2} \mathrm{O}_{5} / \mathrm{MgO}$ catalysts with different Mo doping amounts. (a) $\mathrm{VMgO}$, (b) $3 \mathrm{Mo}-\mathrm{VMgO}$, (c) $5 \mathrm{Mo}-\mathrm{VMgO}$. (*) $\mathrm{MgO}$, JCPDS no. 45-0946; (•) $\mathrm{Mg}_{3}\left(\mathrm{VO}_{4}\right)_{2}$, JCPDS no. 19-0778.

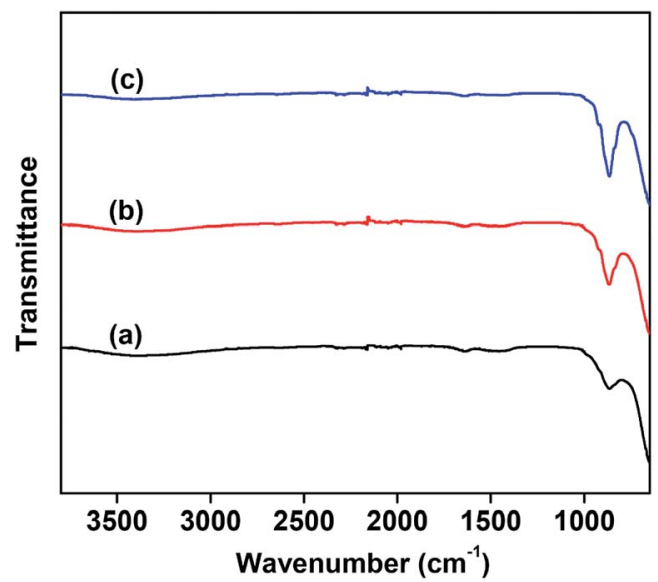

Fig. 2 FTIR spectra of the $10 \mathrm{wt} \% \mathrm{~V}_{2} \mathrm{O}_{5} / \mathrm{MgO}$ catalysts with different $\mathrm{Mo}$ doping amounts. (a) $\mathrm{VMgO}$, (b) $3 \mathrm{Mo}-\mathrm{VMgO}$, (c) $5 \mathrm{Mo}-\mathrm{VMgO}$. which correspond to the stretching vibration of $\mathrm{VO}_{4}{ }^{3-} \cdot \cdot^{32}$ As shown in Fig. 2, the stretching vibration of $\mathrm{VO}_{4}{ }^{3-}$ becomes stronger with the increase in Mo content. The FTIR results are consistent with those of XRD, further confirming the absence of metavanadate and pyrovanadate phases except for the $\mathrm{Mg}_{3}\left(\mathrm{VO}_{4}\right)_{2}$ phase.

The number of basic sites and the basic strength that significantly affect the $\mathrm{CO}_{2}$ desorption were measured by means of $\mathrm{CO}_{2}$-TPD. The results are shown in Fig. 3. For comparison, the $\mathrm{CO}_{2}$-TPD curve of the MgO support was also provided, as shown in Fig. 3(a). The VMgO catalyst without Mo doping exhibited a similar desorption peak area to the peak of the MgO support. This suggests that the VMgO catalyst has a similar number of basic sites to that of the $\mathrm{MgO}$ support. The increase in the Mo-doping amount strongly reduced the number of basic sites, but did not obviously change the basic strength since the $\mathrm{CO}_{2}$ desorption peak at about $300{ }^{\circ} \mathrm{C}$ did not shift to high or low temperatures after the Mo-doping. With the increase in the Modoping amount, the $\mathrm{CO}_{2}$ desorption peak area decreased significantly according to the order $5 \mathrm{Mo}-\mathrm{VMgO}<3 \mathrm{Mo}-\mathrm{VMgO}<$ VMgO.

The catalytic behavior of $\mathrm{VMgO}$ and the Mo-doped $\mathrm{VMgO}$ catalysts during the ODH of $n$-butane strongly depends on the redox properties of the $\mathrm{V}$-species. Therefore, the redox properties of the catalysts were characterized by $\mathrm{H}_{2}$-TPR, and the results are shown in Fig. 4. It can be seen that the content of reducible lattice oxygen slightly increases with the increase in Mo-doping amount, while the reduction peak shifts to higher temperatures. This indicates that the $\mathrm{V}-\mathrm{O}$ bonding energy increases with the addition of Mo.

It is generally believed that the $\mathrm{ODH}$ of alkanes requires moderately active lattice oxygen, ${ }^{28,33-35}$ since more highly active lattice oxygen can easily lead to the deep oxidation of alkanes, thus resulting in a low selectivity, while much less active lattice oxygen is responsible for low conversion. The $\mathrm{H}_{2}$ consumption peak appearing at high temperatures suggests that the lattice oxygen of the catalyst is less active upon Mo-doping, as shown

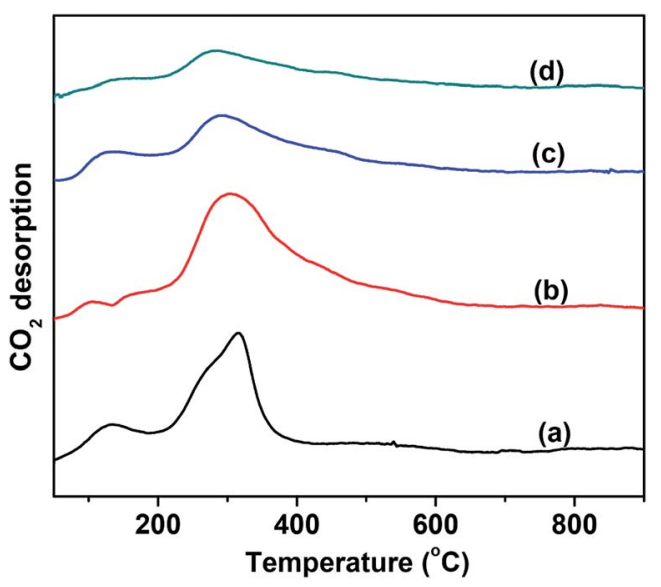

Fig. $3 \mathrm{CO}_{2}$-TPD profiles of the $10 \mathrm{wt} \% \mathrm{~V}_{2} \mathrm{O}_{5} / \mathrm{MgO}$ catalysts with different Mo-doping amounts. (a) $\mathrm{MgO}$, (b) $\mathrm{VMgO}$, (c) $3 \mathrm{Mo}-\mathrm{VMgO}$, (d) $5 \mathrm{Mo}-\mathrm{VMgO}$. 


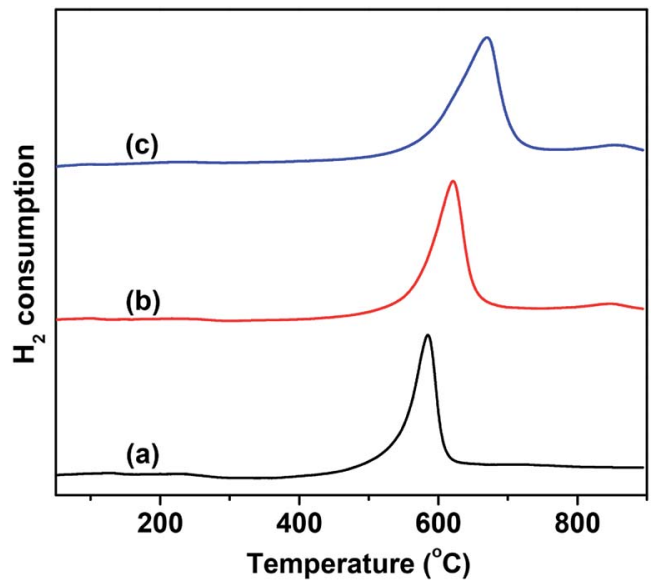

Fig. $4 \mathrm{H}_{2}$-TPR profiles of the $10 \mathrm{wt} \% \mathrm{~V}_{2} \mathrm{O}_{5} / \mathrm{MgO}$ catalysts with different Mo-doping amounts. (a) $\mathrm{VMgO}$, (b) $3 \mathrm{Mo}-\mathrm{VMgO}$, (c) $5 \mathrm{Mo}-$ $\mathrm{VMgO}$

in Fig. 4. As the Mo/V ratio increased from 0 to $5: 100$, the $\mathrm{H}_{2}$ consumption peak gradually shifted from $580{ }^{\circ} \mathrm{C}$ to $630{ }^{\circ} \mathrm{C}$. Therefore, a lower selectivity to $\mathrm{CO}_{x}$ is expected to be achieved on the $5 \mathrm{Mo}-\mathrm{VMgO}$ catalyst due to the lower oxygen lattice reactivity of the $\mathrm{Mg}_{3}\left(\mathrm{VO}_{4}\right)_{2}$ phase, as measured by $\mathrm{H}_{2}$-TPR.

\subsection{Catalytic performance}

3.2.1 Effects of reaction temperature and $\mathrm{C}_{4} \mathrm{H}_{10} / \mathrm{O}_{2}$ molar ratio. Fig. 5 shows a comparison of the catalytic performance of the $\mathrm{VMgO}, 3 \mathrm{Mo}-\mathrm{VMgO}$ and $5 \mathrm{Mo}-\mathrm{VMgO}$ catalysts in the $\mathrm{ODH}$ of $n$-butane to butenes. The catalytic performance of the Mo$\mathrm{VMgO}$ catalysts with different $\mathrm{Mo} / \mathrm{V}$ atomic ratios was studied in the temperature range of $540-660{ }^{\circ} \mathrm{C}$ and at a $\mathrm{C}_{4} \mathrm{H}_{10} / \mathrm{O}_{2}$ molar ratio of $1: 1$. Monobutenes, butadiene, and $\mathrm{CO}_{x}$ were the main carbon-containing products. Some small amounts of other carbon-containing products like $\mathrm{C}_{2}-\mathrm{C}_{3}$ olefins were also detected as by-products of the ODH of $n$-butane.

As expected, with the rising of the temperature the conversion increased, while the selectivity decreased. Furthermore, the selectivity of monobutenes gradually decreased, whereas that of butadiene increased upon increasing temperatures, suggesting that the monobutenes were gradually converted into butadiene during the ODH of $n$-butane. This phenomenon has also been reported by other researchers. ${ }^{{ }^{\mathbf{9} 36-38}}$ The selectivity to total butenes gradually decreased with the rising of temperature. The selectivities to other products, such as $\mathrm{C}_{2}-\mathrm{C}_{3}$, increased with the addition of Mo, indicating that more Modoping leads to cracking reactions. In the temperature range of $540-630{ }^{\circ} \mathrm{C}$, the Mo-free sample, $\mathrm{VMgO}$, acted as the most active catalyst. This result was consistent with the $\mathrm{H}_{2}$-TPR results. At $630{ }^{\circ} \mathrm{C}$, the $n$-butane conversion over the $\mathrm{VMgO}$ catalyst reached $42.8 \%$ at a $\mathrm{C}_{4} \mathrm{H}_{10} / \mathrm{O}_{2}$ molar ratio of $1: 1$. This value was higher than those obtained using $3 \mathrm{Mo}-\mathrm{VMgO}(37.0 \%)$ and $5 \mathrm{Mo}-\mathrm{VMgO}(30.1 \%)$ under the same conditions. Thus, the addition of Mo can decrease the activity of the catalyst, accompanied by an improvement of the selectivity to total butenes and inhibition of the deep oxidation reactions. The total butenes selectivity over the $\mathrm{VMgO}$ catalyst at $630{ }^{\circ} \mathrm{C}$ reached $71.6 \%$, while that on the $3 \mathrm{Mo}-\mathrm{VMgO}$ and $5 \mathrm{Mo}-\mathrm{VMgO}$ catalysts was 75.4 and $79.2 \%$, respectively. For the selectivity to butadiene, the value obtained using the $\mathrm{VMgO}$ catalyst was similar to that of $3 \mathrm{Mo}-\mathrm{VMgO}$ and close to $45 \%$ at $630{ }^{\circ} \mathrm{C}$, while that of $5 \mathrm{Mo}-\mathrm{VMgO}$ was $41.6 \%$. All these catalysts exhibited better performances than those reported in the literature..$^{8,15,26,30,35}$

As discussed above, while the conversion of $n$-butane decreased, the selectivity to total butenes increased with the increase of the Mo-doping amount. This change can be
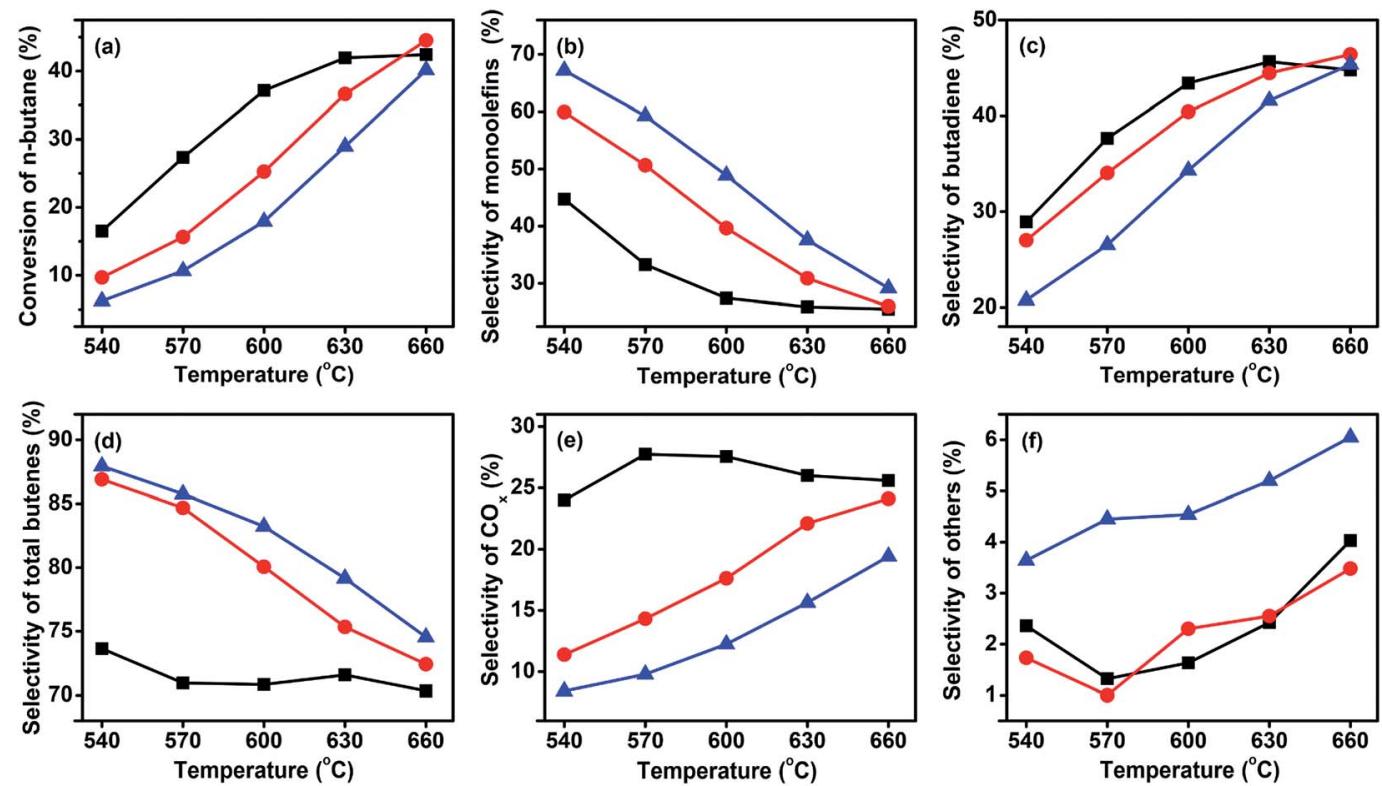

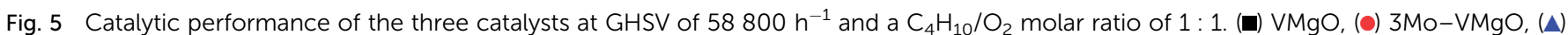
5Mo-VMgO. 
attributed to the fact that the addition of Mo might deactivate part of the high active sites on the catalyst surface and suppress the deep oxidation reactions to produce $\mathrm{CO}_{x}$. Therefore, a small amount of Mo oxide can enhance the $\mathrm{ODH}$ performance of butane, in agreement with other literature reports. ${ }^{31}$

For selective oxidation reactions, the selectivity is usually more important than the conversion; in the presence of a certain catalyst, a higher conversion often means lower selectivity, higher consumption of raw materials, more heat release, and higher risk of thermal runaway, thus the conversion is usually regulated at low levels. The ODH of butane is strongly exothermic, and during our study it was found difficult to control the catalyst bed temperature at a $\mathrm{C}_{4} \mathrm{H}_{10} / \mathrm{O}_{2}$ ratio lower than 1 . Thus, the three catalysts were tested at a higher $\mathrm{C}_{4} \mathrm{H}_{10} /$ $\mathrm{O}_{2}$ ratio. Fig. 6 shows the performance of the three catalysts at $\mathrm{a} \mathrm{C}_{4} \mathrm{H}_{10} / \mathrm{O}_{2}$ molar ratio of $1.5: 1$. In comparison to the reaction at a $\mathrm{C}_{4} \mathrm{H}_{10} / \mathrm{O}_{2}$ molar ratio of $1: 1$, an increase of total butenes selectivity was accompanied by a slight decrease of butane conversion. For example, for the $3 \mathrm{Mo}-\mathrm{VMgO}$ catalyst at $630{ }^{\circ} \mathrm{C}$ and $\mathrm{C}_{4} \mathrm{H}_{10} / \mathrm{O}_{2}$ molar ratio of $1: 1$, the total butenes selectivity and the butane conversion were 75.4 and $37.0 \%$, respectively, while those at a $1.5: 1 \mathrm{C}_{4} \mathrm{H}_{10} / \mathrm{O}_{2}$ molar ratio were 79.3 and $34.5 \%$, respectively.

The catalytic activity of vanadium-based catalysts is closely related to the activity of the lattice oxygen, and it is based on the redox cycle $\mathrm{V}^{5+} \leftrightarrow \mathrm{V}^{4+}{ }^{15,39}$ For the reaction, the lattice oxygen is consumed by oxidation reactions, while being supplied by oxygen gas. The results of the $\mathrm{H}_{2}$-TPR analysis indicate that the addition of Mo to the $\mathrm{VMgO}$ catalyst can increase the reduction temperature of $\mathrm{V}^{5+}$ to $\mathrm{V}^{4+}$, therefore the catalytic activity is reduced but accompanied by an improvement of the selectivity to total butenes. A small amount of Mo-doping can significantly improve the selectivity to total butenes, however further additions of Mo can lead to an increase of cracking reactions. As shown in Fig. 5 and 6, when the Mo/V ratio was $3: 100$, no effect on the cracking reactions was observed, while a significant increase in the selectivity to total butenes was noticed. However, as the $\mathrm{Mo} / \mathrm{V}$ ratio slightly increased to $5: 100$, the selectivity to cracking reactions was more than doubled. The results of the $\mathrm{CO}_{2}$-TPD experiments indicate that the Mo-doping reduced the number of basic sites on the catalysts, thus higher levels of Modoping might promote the cracking reactions. Dejoz et al. found that the Lewis acid sites increased with the addition of Mo to the $\mathrm{VMgO}$ catalyst, and reported a similar finding in their study, i.e., that the selectivity of the cracking reactions increased with Mo-doping increases..$^{15}$ Therefore, the optimal Mo/V ratio for the Mo-VMgO catalysts is $3: 100$ by considering the $n$-butane conversion and total butenes selectivity.

3.2.2 Effect of contact time. A series of tests were performed to investigate the effect of the contact time on the performance of the $3 \mathrm{Mo}-\mathrm{VMgO}$ catalyst at $630{ }^{\circ} \mathrm{C}$. As shown in Fig. 7, the $n$-butane conversion increased from 34.1 to $36.3 \%$, while the selectivity to total butenes decreased from 77.7 to $75.5 \%$ with the contact time increasing from 42.9 to $150 \mathrm{~ms}$. Usually, under the condition that the amount of oxygen is enough for the oxidation reactions to occur, the conversion decreases by shortening the contact time, and it is accompanied by an increase of oxidation product selectivity. The results are consistent with this conclusion. Though longer contact times are favourable for the conversion of $n$-butane which lead to lower selectivity of total butenes. While decrease the contact time between $n$-butane and catalyst, the generated butenes would timely escape from the surface of the catalyst which would give rise to the higher butenes selectivity. In addition, the conversion and selectivity not change obviously with contact time because the conversion of butane is limited by the insufficient oxygen, i.e. no oxygen remaining in the products.
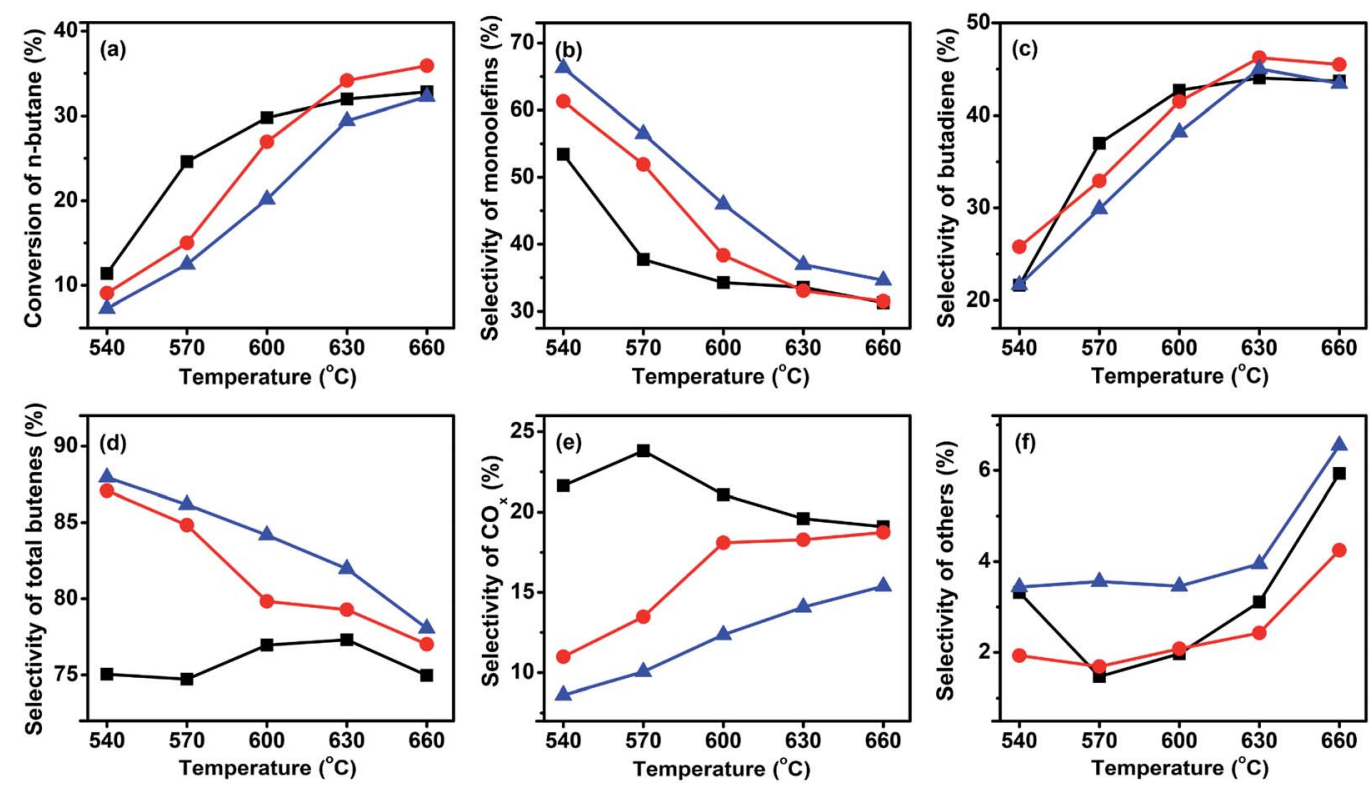

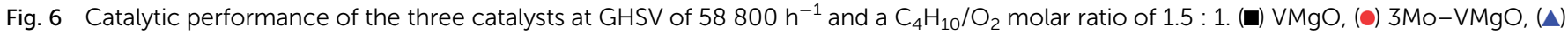
$5 \mathrm{Mo}-\mathrm{VMgO}$. 


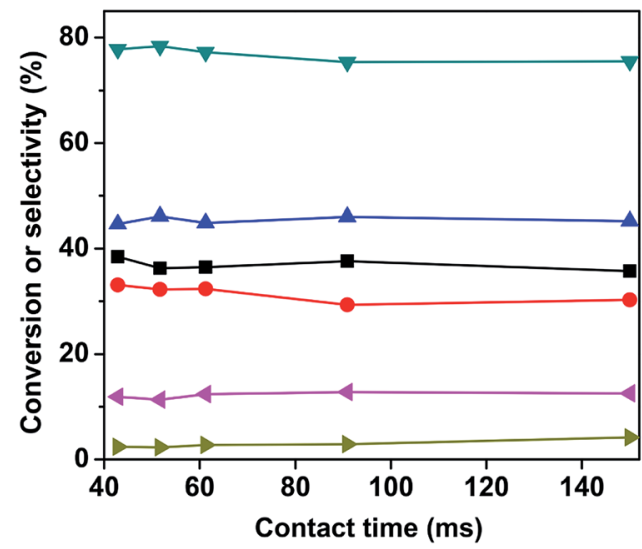

Fig. 7 Effect of the contact time on the catalytic performance. Reaction conditions: $630{ }^{\circ} \mathrm{C}, \mathrm{C}_{4} \mathrm{H}_{10} / \mathrm{O}_{2}$ molar ratio $=1.5: 1$. (口) $n$ Butane conversion, $(\boldsymbol{\nabla})$ total butenes selectivity, ( $\boldsymbol{\Delta}$ ) butadiene selectivity, (๑) monoolefin selectivity, $(\triangleleft) \mathrm{CO}_{x}$ selectivity, $(\downarrow)$ other products selectivity.

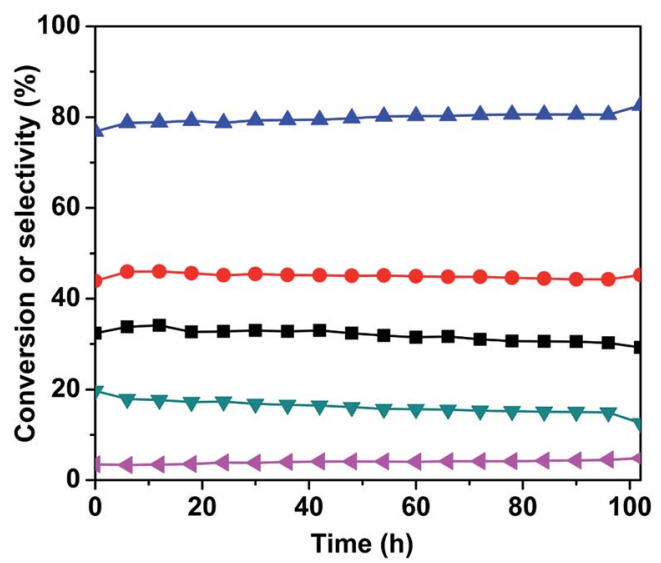

Fig. 8 Stability of the $3 \mathrm{Mo}-\mathrm{VMgO}$ catalyst. Reaction conditions: at GHSV of $58800 \mathrm{~h}^{-1}, 630{ }^{\circ} \mathrm{C}, \mathrm{C}_{4} \mathrm{H}_{10} / \mathrm{O}_{2}$ molar ratio $=1.5: 1$. (口) $n$ Butane conversion, $(\boldsymbol{\Lambda})$ total butenes selectivity, (๑) butadiene selectivity, $(\nabla) \mathrm{CO}_{x}$ selectivity, $(\varangle)$ other products selectivity.

3.2.3 Stability of the 3Mo-VMgO catalyst. The stability of the $3 \mathrm{Mo}-\mathrm{VMgO}$ catalyst was tested at the $\mathrm{C}_{4} \mathrm{H}_{10} / \mathrm{O}_{2}$ molar ratio of $1.5: 1$ and $630{ }^{\circ} \mathrm{C}$, and the results are shown in Fig. 8. As it can be seen, the conversion of $n$-butane was maintained around $34 \%$, the total butenes selectivity remained close to $80 \%$, and the butadiene selectivity was around $45 \%$ within the first $50 \mathrm{~h}$. After $50 \mathrm{~h}$, the $n$-butane conversion and butadiene selectivity decreased slightly, however the total butenes selectivity gradually increased. This change in conversion and selectivity was related to the catalyst sintering, which resulted in the reduction of the specific surface area (as shown in Table 1) and number of active sites.

\section{Conclusions}

Mo-Doped $\mathrm{VMgO}$ catalysts containing $\mathrm{Mg}_{3}\left(\mathrm{VO}_{4}\right)_{2}$ as the only vanadate phase were prepared by an impregnation method. BET surface area tests revealed that the Mo-doped catalysts possessed a lower surface area as comparing to the undoped sample. $\mathrm{H}_{2}$-TPR and $\mathrm{CO}_{2}$-TPD results indicated that the Modoping improved the redox temperature, while decreasing the number of basic sites. On the basis of the $n$-butane ODH catalytic tests, it was found that the addition of a small amount of Mo effectively improved the selectivity of butenes and inhibited the deep oxidation reactions. However, further addition of Mo decreased the catalyst activity, leading to an increase in the selectivity of cracking reactions. Therefore, the optimal Mo/V ratio for this series of catalysts was $3: 100$ by considering the $n$-butane conversion and total butenes selectivity. Changing the contact time produced only a slight increase in the selectivities to monoolefins and total butenes. The $3 \mathrm{Mo}-\mathrm{VMgO}$ catalyst maintained a stable performance during the initial $50 \mathrm{~h}$, but it then underwent a gradual deactivation due to sintering, which induced a reduction of the active sites.

\section{Acknowledgements}

The authors gratefully acknowledge financial support from the Fundamental Research Program for Clean Energy and National Natural Science Foundation of China (21476101), Youth Innovation Promotion Association of the Chinese Academy of Sciences, the Strategic Priority Research Program of the Chinese Academy of Sciences (Grant No. XDB17020400) and Dalian Institute of Chemical Physics (DICP DMTO201503).

\section{References}

1 Y. B. Xu, J. Y. Lu and J. D. Wang, Progr. Chem., 2007, 19, 14811487.

2 E. Finocchio, G. Ramis, G. Busca, V. Lorenzelli and R. J. Willey, Catal. Today, 1996, 28, 381-389.

3 S. D. Jackson and S. Rugmini, J. Catal., 2007, 251, 59-68.

4 P. R. Pujado, B. V. Vora and C. Make, Hydrocarbon Process., 1990, 69, 65-72.

5 S. S. Choi and Y. K. Kim, J. Ind. Eng. Chem., 2011, 17, 394-396.

6 L. H. Duan, X. H. Gao, X. H. Meng, H. T. Zhang, Q. Wang, Y. C. Qin, X. T. Zhang and L. J. Song, J. Phys. Chem. C, 2012, 116, 25748-25756.

7 G. Raju, B. M. Reddy, B. Abhishek, Y.-H. Mo and S.-E. Park, Appl. Catal., A, 2012, 423, 168-175.

8 J. M. López Nieto, A. Dejoz, M. I. Vázquez, W. O'Leary and J. Cunningham, Catal. Today, 1998, 40, 215-228.

9 J. M. López Nieto, P. Concepción, A. Dejoz, H. Knözinger, F. Melo and M. I. Vázquez, J. Catal., 2000, 189, 147-157.

10 O. Rubio, J. Herguido and M. Menéndez, Chem. Eng. Sci., 2003, 58, 4619-4627.

11 R. Vidal-Michel and K. L. Hohn, J. Catal., 2004, 221, 127-136.

12 N. Kijima, M. Toba and Y. Yoshimura, Catal. Lett., 2009, 127, 63-69.

13 S. Ge, C. Liu, S. Zhang and Z. Li, Chem. Eng. J., 2003, 94, 121126.

14 A. Costine and B. K. Hodnett, Appl. Catal., A, 2005, 290, 9-16.

15 A. Dejoz, J. M. López Nieto, F. Márquez and M. I. Vázquez, Appl. Catal., A, 1999, 180, 83-94. 
16 N. Madaan, R. Haufe, N. R. Shiju and G. Rothenberg, Top. Catal., 2014, 57, 1400-1406.

17 N. Madaan, N. R. Shiju and G. Rothenberg, Catal. Sci. Technol., 2016, 6, 125-133.

18 Z. Strassberger, E. V. Ramos-Fernandez, A. Boonstra, R. Jorna, S. Tanase and G. Rothenberg, Dalton Trans., 2013, 42, 5546-5553.

19 B. Xu, X. F. Zhu, Z. W. Cao, L. N. Yang and W. S. Yang, Chin. J. Catal., 2015, 36, 1060-1067.

20 O. Rubio, J. Herguido and M. Menéndez, Chem. Eng. Sci., 2003, 58, 4619-4627.

21 R. Vidal-Michel and K. L. Hohn, J. Catal., 2004, 221, 127-136.

22 N. Kijima, M. Toba and Y. Yoshimura, Catal. Lett., 2009, 127, 63-69.

23 S. Ge, C. Liu, S. Zhang and Z. Li, Chem. Eng. J., 2003, 94, 121126.

24 Y. Wang, S. H. Xie, B. Yue, S. J. Feng and H. Y. He, Chin. J. Catal., 2010, 31, 1054-1060.

25 Y. F. Liu, X. P. Wang, F. P. Tian and C. Y. Yia, Chin. J. Catal., 2004, 25, 721-776.

26 R. Liu, X. P. Wang, C. Y. Jia and W. Shi, Chin. J. Catal., 2005, 26, 650-654.

27 J. K. Lee, H. Lee, U. G. Hong, J. Lee, Y.-J. Cho, Y. Yoo, H.-S. Jang and I. K. Song, J. Ind. Eng. Chem., 2012, 18, 1096-1101.
28 J. Rischard, C. Antinori, L. Maier and O. Deutschmann, Appl. Catal., A, 2016, 511, 23-30.

29 A. Barrera, K. Muramatsu, T. Viveros, S. Gomez, J. A. Montoya, P. del Angel, G. Pérez and J. Campa Molina, Appl. Clay Sci., 2009, 42, 415-421.

30 N. Kijima, M. Toba and Y. Yoshimura, Catal. Lett., 2009, 127, 63-69.

31 C. Caro, K. Thirunavukkarasu, M. Anikumar, N. R. Shiju and G. Rothenberg, Adv. Synth. Catal., 2012, 354, 1327-1336.

32 X. Y. Fu, S. Y. Niu, H. W. Zhang and Q. Xin, Spectrosc. Spectral Anal., 2006, 26, 27-29.

33 C. Téllez, M. Abon, J. A. Dalmon, C. Mirodatos and J. Santamaría, J. Catal., 2000, 195, 113-124.

34 M. E. Harlin, V. M. Niemi and A. O. I. Krause, J. Catal., 2000, 195, 67-78.

35 H. Lee, J. K. Lee, U. G. Hong, Y. Yoo, Y.-J. Cho, J. Lee, H.-S. Jang, J. C. Jung and I. K. Song, J. Ind. Eng. Chem., 2012, 18, 808-813.

36 A. A. Lemonidou, G. J. Tjatjopoulos and I. A. Vasalos, Catal. Today, 1998, 45, 65-71.

37 B. Solsona, F. Ivars, P. Concepción and J. M. López Nieto, J. Catal., 2007, 250, 128-138.

38 N. C. Ramani, D. L. Sullivan and J. G. Ekerdt, J. Catal., 1998, 173, 105-114.

39 T. Blasco and J. M. López Nieto, Appl. Catal., A, 1997, 157, 117-142. 